\title{
NO CENTENARIO DE CREACIÓN DO INSTITUTO-ESCOLA: REALIZACIÓNS EDUCATIVAS DOS INSTITUCIONISTAS
}

\author{
IN THE CENTENARY OF THE INSTITUTE - SCHOOL: \\ INSTITUTIONISM' EDUCATIONAL ACCOMPLISHMENTS
}

http://dx.doi.org/10.15304/ie.28.5481

\author{
Anxo Serafín Porto Ucha \\ Dpto. de Pedagoxía e Didáctica \\ Universidade de Santiago de Compostela \\ angelserafin.porto@usc.es
}

Raquel Vázquez Ramil

Dpto. de Didáctica de las Ciencias Experimentales,

Sociales y de la Matemática

Universidad de Valladolid

mariaraquel.vazquez@uva.es

\begin{abstract}
Era el Abuelo, el pobre Abuelo, el que soñaba lo que se debía hacer, $y$ casi en forma de quejas y suspiros, hacía llegar su influjo a los amigos que eran de la Junta o a los amigos de los amigos de los amigos (... $)^{1}$.
\end{abstract}

\section{RESUMO}

En 1876 creábase en Madrid a Institución Libre de Enseñanza2 (ILE). Pero a ILE non foi soamente unha experiencia educativa creada en Madrid, que mantivo viva a súa actividade renovadora e innovadora durante 60 anos (1876-1936). Foron tamén Institución outros centros que puxeron en práctica as ideas pedagóxicas de Francisco Giner de los Ríos e dos seus máis inmediatos colaboradores.

O obxectivo do presente traballo é diferenciar e analizar sucintamente algunhas das realizacións educativas creadas por influencia da ILE, entre elas e en especial o Instituto-Escola, do que este ano se celebra o centenario da súa creación (1918). Hai igualmente no presente traballo un esforzo de análise da vinculación de Galicia con eses proxectos renovadores.

Recibido: 23/IX/2018. Aceptado: X/2018

1 Pijoán, J. (1928). Mi don Francisco Giner. BILE, LII, pp. 73-74.

2 Mantemos para a ILE o seu nome completo en castelán. 
A nivel documental, a fonte primaria principal foi o Fondo Giner de los Ríos, depositado na Real Academia da Historia, o Boletín de la Institución Libre de Enseñanza (BILE), as Memorias da Junta para Ampliación de Estudios e Investigaciones Científicas (JAE) e documentación dos Arquivos da Residencia de Estudiantes e da Residencia de Señoritas, entre outras fontes primarias (AHUS, Fundación Penzol, Misión Biolóxica, etc.) e secundarias produto das nosas esculcas de investigación sobre esta temática.

Palabras-chave: Institución Libre de Enseñanza, Francisco Giner de los Ríos, renovación pedagóxica, innovación educativa, Instituto-Escola.

\section{ABSTRACT}

In 1876 was born in Madrid the Institución Libre de Enseñanza (ILE). But ILE was not just an educational experience created in Madrid, which kept its renovator and innovative activity during 60 years (1876-1936). Other centres were also set up that put into practice the pedagogical ideas of Francisco Giner de los Ríos and his closest collaborators. The aim of its work is to differentiate and analyze briefly some of the educational achievements created under the ILE's influence, and especially the Institute-School, which this year celebrates the centenary of its creation in 1918.

Furthermore, the present work analyzes the linkage of Galicia with these renovator projects. At the documentary level, the primary source was the Giner de los Ríos' documentary collection, deposited in the Spanish Royal Academy of History, the Institución Libre de Enseñanza Bulletin (BILE), the Junta para Ampliación de Estudios Reports (JAE), and documentation from the Students and Ladies Residences. There are also other primary sources (AHUS, Penzol Foundation, Galician Biological Mission, etc.) and secondary ones, which we have investigated during a long time till now.

Keywords: Institución Libre de Enseñanza, Francisco Giner de los Ríos, Pedagogical Renovation, Educational Innovation, Institute-School.

\section{INTRODUCIÓN}

Nos sesenta anos de existencia da ILE, entendida non só como centro docente, senón como realidade máis ampla, poden considerarse tres períodos (Tuñón de Lara, 1984:44-45): o primeiro, de apertura liberal, remata en 1881. Coincide coa chegada de José Luis Albareda ao Ministerio de Fomento e a volta ás súas cátedras dos profesores deportados con motivo da política retrógrada de Orovio nos comezos da Restauración, que dera orixe á ILE (1876). A Institución deixa de ser entón un centro de ensinanza universitaria, permanecendo a continuidade entre a primeira e a segunda ensinanza, incluídos os párvulos a partir de 1884. O segundo período ocupa o último terzo do século XIX, ata a fundación da Junta para Ampliación de Estudios e Investigaciones Científicas (en adiante, JAE), en 1907. Durante este período teñen lugar toda unha serie de incursións político-sociais dos institucionistas. A través deles, Giner aconsella e intervén indirectamente en proxectos parlamentarios. Xorde nesa época o Rexeneracionismo, que denuncia o problema dos males de España e propón solucións. Son os anos de afianzamento do socialismo español con Pablo Iglesias. Ao crearse o Instituto de Reformas Sociais (1903), o institucionismo incide na política social. Aparece tamén a chamada «Extensión Universitaria» na Universidade de Oviedo, a partir da creación da Escola práctica de Estudos xurídicos e sociais (1896), con Aniceto Sela, Adolfo Álvarez Buylla, Leopoldo Alas «Clarín», Adolfo González Posada e Rafael Altamira. Estes homes, xunto a outros institucionistas, 
como Manuel Bartolomé Cossío ou Rafael María de Labra, participan na ensinanza e imparten conferencias nos diferentes centros extrauniversitarios. Coa creación da JAE, que vai exercer a súa influencia dentro do aparato do Estado, inaugúrase para a ILE unha terceira época que abarca ata 1936 (Capitán Díaz, 1994: 451-477) e o corte da guerra civil. A Orde de disolución da ILE publícase no Boletín Oficial del Estado de 28 de maio de 1940.

A Institución Libre de Enseñanza non foi, pois, soamente un centro creado en Madrid. Foron tamén Institución outros centros que puxeron en práctica as ideas pedagóxicas de Giner de los Ríos, tanto dende a iniciativa privada como dende a estatal (Jiménez García, 2002: 162-164): O Museo Pedagóxico Nacional, a Corporación de Antigos Alumnos da ILE, as Colonias Escolares, as Conferencias dominicais, as Asembleas de mestres, a Extensión Universitaria, o Instituto de Reformas Sociais, a JAE e as institucións nacidas ao seu redor (o Centro de Estudos Históricos, diversos Institutos de investigación, as Residencias de Estudantes e de Señoritas, os «laboratorios en provincias» -entre eles a Misión Biolóxica de Galicia-, a Escola de Párvulos de Simancas, varias cátedras no estranxeiro,etc.), a Escola Superior do Maxisterio,a Dirección Xeral de Primeira Ensinanza, a Fundación Giner de los Ríos, a Fundación «Sierra-Pambley», as Misións Pedagóxicas, etc.

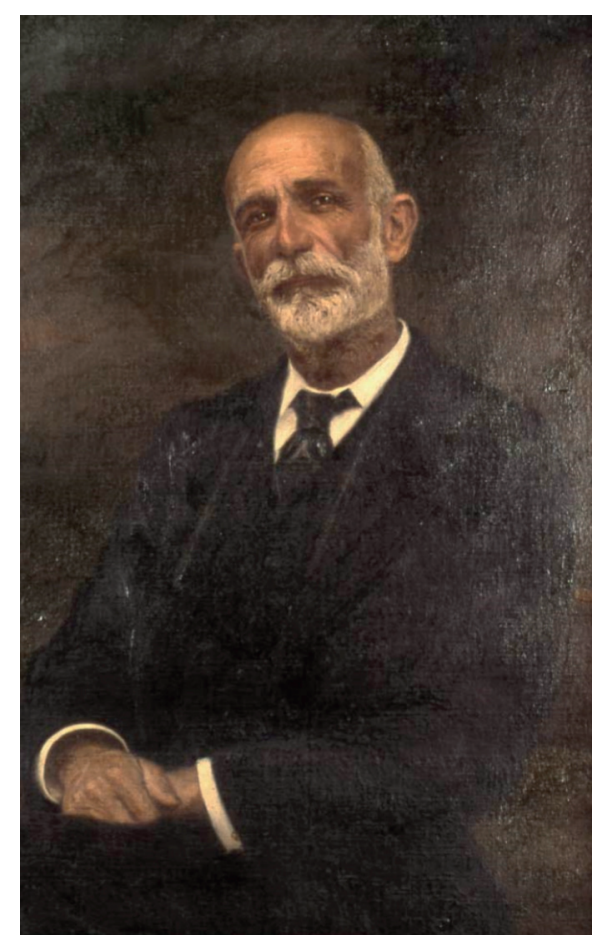

Figura 1. Retrato de Francisco Giner de los Ríos (1913), inspirador da fusión entre os distintos niveis do ensino. Obra de Juan José Gárate Clavero. Colección de Patrimonio Histórico Artístico da Universidade Complutense de Madrid. 


\section{AS PRIMEIRAS REALIZACIÓNS EDUCATIVAS DOS INSTITUCIONISTAS (S. XIX)}

\subsection{O Museo Pedagóxico Nacional}

O Museo foi creado por R.D. de 6 de maio de 1882, co nome de Museo de Instrución Primaria, para contribuír ao estudo dos problemas modernos da pedagoxía, dar a coñecer en España o movemento pedagóxico do estranxeiro e axudar á formación dos mestres e mestras. O primeiro director do Museo foi Manuel B. Cossío, discípulo predilecto e seguidor da obra de Giner. Con carácter interino ata o nomeamento de Cossío en propiedade (1883), foi director Pedro de Alcántara García. En 1894 pasou a denominarse Museo Pedagóxico Nacional. O Museo centrou o seu obxectivo na renovación metodolóxica dos procedementos tradicionais da ensinanza, á luz das novas tendencias psicolóxicas. Organizaba conferencias, cursos breves para o maxisterio, principalmente sobre aspectos dos que eran deficitarias as Escolas Normais; editaba monografías; contaba con proxectos, planos de edificios e mobiliario escolar (entre outros, os «pupitres» que moitos coñecemos); proporcionaba informes ao redor da organización e construción de escolas e dispoñía dunha importante biblioteca circulante de instrución primaria. Aínda que foi unha creación oficial, pode considerarse produto da Institución Libre de Enseñanza. Lonxe de ser un arquivo morto ou un simple museo escolar con afáns coleccionistas (García del Dujo, 1985), converteuse en centro de información e difusión técnico-pedagóxica en todos os sentidos. Manuel B. Cossío dirixiu o Museo ata 1929, sendo logo director honorario ata a súa morte (1935); o sucedeu Domingo Barnés, secretario con anterioridade, que será ministro de Instrución Pública na Segunda República (1933).

Naquel contexto, non é estraño, pois, que no R.D. de 23 de setembro de 1898, polo que o ministro de Fomento Germán Gamazo emprendía a reforma das Escolas Normais, ao referirse no art. $6^{\circ}$ aos cambios metodolóxicos, dispuxese:

En cada escuela normal habrá un museo pedagógico, que se formará, siempre que sea posible, con modelos reducidos de los objetos útiles para la enseñanza.

Dirigirá esta Museo el Director/a de la Escuela Normal. El Director de la Escuela Normal Central determinará la clase y número de conferencias que han de darse en el Museo Pedagógico Nacional, el cual conservará su actual organización. La mayor parte de estas conferencias deberán versar sobre el examen y crítica del material de enseñanza y del mobiliario escolar de moderna construcción.

A título de exemplo e cumprindo este precepto, Casto Blanco Cabeza, director a principios de século da Escola Normal Superior de Santiago de Compostela, impulsou a creación dun Museo Pedagóxico no propio centro, logrando xuntar máis de 400 exemplares interesantes, entre libros e outros obxectos; labor iniciada sendo mestre de escola pública en Tui na última década do XIX, onde organizou un museo e un xardín botánico escolar (Porto Ucha, 2014: 99-104). A nivel galego destacou tamén a figura do betanceiro Francisco Vales Villamarín, de influencias institucionistas, que cursara os seus estudos na Escola Normal Superior de Santiago de Compostela, e que fundou en 1926 o Museo Pedagóxico Rexional na Coruña.

A chegada da guerra civil deu ao traste con aquela loable experiencia do Museo Pedagóxico Nacional. O 29 de marzo de 1941 extinguiuse a organización científica e administrativa do Museo, pasando a súa biblioteca, traballos e material ao Instituto «San José de Calasanz», integrado no Consello Superior de Investigacións Científicas (CSIC). 


\subsection{As Colonias Escolares}

As Colonias Escolares veñen considerándose como unha institución iniciada en 1876 polo pastor evanxelista suízo Walter Bion. En España, Cossío decidiu realizar a primeira Colonia Escolar do Museo Pedagóxico Nacional en 1887, en San Vicente de la Barquera (Santander). A esta colonia seguíronlle pouco despois as da Corporación de Antigos Alumnos da ILE. Dende 1910, as Colonias do Museo Pedagóxico trasladáronse ao Mosteiro de San Antolín de Bedón (Asturias), dirixidas por Ángel do Rego, fillo de galegos de Viveiro, e a súa dona, Elvira Alonso Moreno, moi vinculados á ILE (Porto Ucha, 1986: 195-245).

O exemplo rendeu. A nivel oficial, a R.O. de 26 de xullo de 1892 sobre Colonias Escolares levou á Sociedade Económica de Amigos do País de Santiago a organizar a Primeira Colonia Escolar Compostelá en 1893 (Costa Rico, 1994), no Colexio Santiago Apóstol dos PP. da Compañía de Xesús, en Camposancos (A Guarda, Pontevedra), despois duns días en Vilagarcía. Nunha circular do ano seguinte, o Director Xeral de Instrución Pública, o galego Eduardo Vincenti, facía unha chamada de atención sobre os exercicios militares observados e mostrábase partidario das colonias mixtas, recomendando buscar sitios de clima doce ao lado do mar, como Pontevedra, Marín, Vilagarcía, Vilaxoán e Vigo.

Relacionadas cos institucionistas galegos, hai que destacar as colonias iniciadas na Lagoa en 1902, na estrada de Sada a Betanzos, grazas aos promotores, José López Cortón, José Gutiérrez del Arroyo e Ramón Tenreiro, con nenos procedentes das escolas municipais da Coruña. Contaron coa orientación directa de Francisco Giner de los Ríos e de Cossío, aproveitando a estadía destes na quinta San Vitorio que a familia da muller de Cossío, Carmen López Cortón, tiña en San Fiz de Vixoi (Bergondo). Máis tarde, crearíase un Padroado Local de Colonias, dirixido por Juan García Niebla e Marcelino Pedreira (Costa Rico e Benítez García, 1999).

Son de destacar, igualmente, as Colonias Escolares da Universidade de Santiago de Compostela, en Rianxo, entre 1923 e 1925, supervisadas polo Inspector Xefe de Ensinanza Primaria da provincia de Lugo, Manuel Lorenzo Gil (Porto Ucha, 1991). En Vigo, a partir de 1904, o institucionista Fernando García Arenal, xunto con Fernando Conde e Ramón Gil, impulsou as primeiras Colonias, primeiro no Carballiño e na Estrada, e logo no Rebullón, en Tameiga (Mos), coa axuda da Caixa de Aforros de Vigo (Pereira Domínguez, 1991).

Dende o Ministerio de Instrución Pública, un Real Decreto de 1911 encargaba a organización das Colonias Escolares á Dirección Xeral de Primeira Ensinanza. En Ferrol, grazas ao Inspector Luciano Seoane Seoane e ao Padroado de Cantinas e Colonias Escolares de Ferrol, a primeira Colonia de Vacacións trasladouse a Valdoviño en 1927, e a Cedeira, Piñeiro e A Cabana, nos anos seguintes. En Lugo, o Inspector Manuel Lorenzo Gil emprendía as primeiras actividades en 1912, con saídas a Foz e Barreiros. A Revista Vida Escolar informaba en 1927 sobre o labor do Padroado de Protección Escolar Lucense e do Inspector Luis Soto Menor. En 1928 saían para a praia de Benquerencia un total de 52 nenos e nenas. En 1932, a Colonia veraneaba en Santiago de Reinante.

En Pontevedra, a pesar dos esforzos de Vincenti dende a Asociación Pedagóxica de Mestres, non se celebrou a primeira Colonia Escolar ata 1925, no edificio que os Fillos de Lalín en América 
construíran para Hospital-Asilo. En 1927 e 1928 trasladáronse a Ponte Caldelas. Entre outros lugares, funcionaron tamén Colonias para nenos enfermos e tuberculosos no Sanatorio Marítimo da Lanzada.

Ourense, debido a ser zona do interior e ás preferencias polos baños de mar, contou con menos iniciativas, aínda que se beneficiou do Sanatorio Marítimo Nacional de Oza (A Coruña). Houbo propostas de enviar aos nenos ao Mosteiro de San Pedro de Rocas, que non prosperaron. Destacou, sen embargo, o labor da Inspectora Antonia Ortiz Currais na creación de mutualidades escolares en Trives e Ribadavia.

Durante a Segunda República incrementáronse as accións deste tipo. Hai que destacar, incluso, a incautación dos bens da Compañía de Xesús en Oia, Camposancos e Teis, para utilización dos edificios para Colonias, ou ben como lugar de repouso dos mestres e mestras. Esta proposta de Fernando de los Ríos, Ministro de Instrución Pública no bienio azañista, se ben foi acollida favorablemente por distintos concellos e consellos locais de primeira ensinanza, finalmente non seguiu adiante.

Estas iniciativas tiveron a súa continuación despois da guerra civil, aínda que dende perspectivas distintas.

\subsection{A Extensión Universitaria}

Este movemento foi esencialmente obra dos medios liberais a finais do século XIX. Ao mesmo tempo que se preocupou pola educación das clases obreiras, supuxo un cambio na mentalidade tradicional sobre o funcionamento da Universidade, estendéndoa más alá das aulas (Jiménez Eguizábal, 1985: 133-135).

A Extensión Universitaria encontrou na ILE un medio socio-institucional de recepción, difusión e impulso. O institucionista Rafael Altamira presentou ao Congreso hispano-portugués-americano de Madrid de 1892 un informe, no que estimaba que era misión da Universidade reivindicar a extensión da cultura xeral ao pobo, a comunicación directa «con las clases sociales que no concurren a sus cátedras»». O Congreso emitiu un voto para que se desenvolvese en España esta iniciativa, que foi rapidamente recollida pola Corporación de antigos alumnos da ILE. En 1896, creouse na Universidade de Oviedo unha Escola práctica de Estudos xurídicos e sociais. Puxéronse en marcha unha serie de conferencias e excursións. Era o precedente do nacemento da Extensión Universitaria. Xorde, así, a Extensión Universitaria en Oviedo, que se aprobou en Sesión do Claustro de 11 de outubro de 1898.

O éxito da Extensión Universitaria en Oviedo, xunto ao esforzo de distintos grupos, axudan a explicar a implantación das Extensións Universitarias de Barcelona, Madrid, Salamanca, Santander, Sevilla, Valencia e Zaragoza. Xunto aos anteriormente citados, outros institucionistas como Cossío o Rafael $\mathrm{M}^{\mathrm{a}}$ de Labra participaron na ensinanza e impartiron conferencias. A Extensión Universitaria contou en moitos casos coa colaboración de escritores, artistas e outros intelectuais; Ateneos, Círculos culturais e outras fundacións próximas ao pobo foron lugar de encontro destas actividades. 


\subsection{O Instituto de Reformas Sociais}

Entre os centros de inspiración institucionista, en 1903 créase o Instituto de Reformas Sociais, baixo a dirección de Gumersindo de Azcárate, nun goberno conservador de Francisco Silvela. Tiña como antecedente a Comisión de Reformas Sociales, creada en 1890 e impulsada por Segismundo Moret. O Instituto foi fundado para preparar a lexislación do traballo así como para favorecer a acción social dirixida á mellora e benestar social das clases traballadoras.

O nomeamento de Gumersindo de Azcárate, membro da Institución Libre de Enseñanza non foi casual, pois a ILE destacárase na defensa da intervención do Estado para resolver a cuestión social, tema tamén tratado dende a doutrina da Igrexa, do catolicismo social e a Rerum Novarum en España (de la Cueva e Montero, 2007). O Instituto tiña tres seccións: a de lexislación e información bibliográfica a cargo de Adolfo Posada; a de estatísticas, dirixida por Adolfo Buylla; e a de inspección xeral, encargada ao xeneral Marvá.

Trala morte de Gumersindo de Azcárate (1917), o Instituto de Reformas Sociais viviu un proceso de crise, paralelo ao do réxime político que o creara. En 1924 foi suprimido pola Ditadura de Primo de Rivera.

\subsection{As Universidades Populares}

Aínda que cun carácter distinto á Extensión Universitaria, as Universidades Populares xurdiron vinculadas a aquela iniciativa. Con carácter privado, foron institucións obreiras de marcado signo político-social e sindical. Adolfo González Posada, Catedrático de Dereito político na Universidade ovetense, un dos principais artífices da creación da Escola práctica de Estudos xurídicos e sociais e da Extensión Universitaria, co seu traslado a Madrid (1904) quedou tamén adscrito ao Instituto de Reformas Sociais. Participou con Álvarez Buylla na Universidade popular madrileña.

Non é casualidade, pois, que a primeira Universidade Popular en España apareza en Oviedo en 1901, arredor do grupo de profesores da Universidade (Buylla, Canella, Altamira, Posada...) Por obra de Blasco Ibáñez, Valencia crea a súa Universidade Popular en 1903. Séguenlle Madrid (1904) e A Coruña (1906) (Capelán Rey, 1999).

A Universidade Popular de A Coruña foi creada en setembro de 1906 por Manuel Durán García e un grupo de mozos e intelectuais republicanos, entre os que destacan Enrique Hervada, Gerardo Abad Conde, Santiago Casares Quiroga, Ángel del Castillo ou Fernando Martínez Morás; na Universidade Popular de A Coruña, que tivo moi en conta as creadas nesa época en Madrid e Valencia, ofrecíanse clases para obreiros de Aritmética, Xeometría, Debuxo xeométrico, Caligrafía, Ortografía e Redacción, Francés ou Inglés, complementadas con cursos de extensión cultural no Centro de Estudos Sociais «Germinal» e na Sociedade de Canteiros e con excursións de índole moi variada. A primeira etapa da Universidade Popular de A Coruña concluíu en 1926, rexurdindo posteriormente durante a Segunda República .

Sendo o seu principal promotor Antonio Machado, Segovia pon en funcionamento a súa Universidade Popular en 1919. Coa chegada da Segunda República, aparece a de Cartagena. O obxectivo era «difundir la instrucción de modo preferente entre los obreros por medio de clases y 
conferencias de divulgación» (Boletín da Universidade Popular de Segovia). Estes centros contaron, primeiro, con profesores universitarios; logo, con profesores de grao medio e a colaboración dalgúns intelectuais de talante liberal (Fernández Soria, 1985: 366-67).

\subsection{A Fundación «Sierra-Pambley»}

Aínda que a maior parte das súas accións teñen lugar xa entrado o século XX, imos dedicarlle un último apartado á creación da Fundación «Sierra-Pambley», con don Francisco FernándezBlanco y Sierra-Pambley (1827-1915) (coñecido por don Paco Sierra, que permaneceu solteiro). A familia contaba con amplas posesións en Madrid, onde don Paco Sierra habitaba durante case todo o ano, e en León, á beira da Catedral, en Hospital de Órbigo, en Moreruela ou en Villablino, onde estaba a que el consideraba a súa casa solariega (López Contrera, 1986: 134-221).

O 21 de abril de 1887 don Paco Sierra funda unha escola en Villablino, en memoria do seu tío don Segundo de Sierra-Pambley, co obxecto de difundir a cultura na súa terra natal, a comarca de Laciana. Crea tamén unha escola de ensinanza mercantil e agrícola en Villablino.

Para dirixir as súas obras benéficas, don Paco Sierra impulsa unha Fundación, da que formaban parte, ademais del mesmo, Gumersindo de Azcárate e Manuel B. Cossío, aínda mozo. Giner de los Ríos tivo moito que ver nesta decisión, «hasta el punto de que se desplaza en un coche de caballos y en pleno invierno de 1886, en unión de Azcárate y Cossío, hasta Villablino, donde, en los escaños de la cocina de leña, se dieron los primeros pasos para llevar a buen fin la idea de D. Paco» (López Contrera, 1986: 138).

O 11 de maio de 1907, don Paco Sierra outorga unha ampliación da Fundación, creando escolas en Hospital de Órbigo, Villameca, León e Moreruela de Tábara. Engádense como novos patróns da Fundación, a Germán Flórez e ao sobriño de D. Paco, Juan Flórez Posada. D. Paco Sierra outorgou varios testamentos. O derradeiro, en Villablino, o 1 de outubro de 1914, pouco antes da súa morte.

Isabel Cantón Mayo no seu estudo dedicado a La Fundación Sierra-Pambley inclúe un apartado sobre «La fuente de Villablino» (1995: 82-84). Lémbranos como a ILE acostumaba homenaxear aos seus homes ilustres cunha fonte. Sabemos que a auga e a natureza son constantes na consideración do krausismo, co que se identifican moitos institucionistas. Segundo a autora, a idea de dedicar unha fonte a D. Paco Sierra retomouse en Villablino en 1932, coa aprobación de Cossío. A fonte ubicouse na praza. Aínda que a fonte xa non existe, serviu de inspiración ao lacianego Luis Mateo Díez para a novela La fuente de la edad (1986), onde os mestres de cantería galegos, os chamados «canteiros» que traballaban por alí, caían con frecuencia, nas veladas nocturnas, ao pilón da fonte creada en homenaxe a D. Paco Sierra en 1935.

Nas nosas investigacións sobre as relacións da Institución Libre con Galicia, na correspondencia do Fondo Giner de los Ríos (Porto Ucha, 1986: 548-550) topámonos coa familia Alvarado de Viveiro (Lugo), xa dende os tempos da fundación da ILE, en que don Francisco Alvarado, avogado figura como un dos primeiros subscritores ao Boletín da Institución. Os Alvarado aparecen relacionados coa Fundación Sierra-Pambley, principalmente con Villablino. Na lista de accionistas da ILE, 
na $1^{\mathrm{a}}$ e $2^{\mathrm{a}}$ emisión, figura Salustio Víctor Alvarado, segundo recolle o BILE (1883). Salustio Víctor Alvarado morreu en Valladolid en 1886, sendo fiscal da Audiencia. Deputado nas Cortes constituíntes de 1869, fora tamén Gobernador Civil de Lugo durante o Sexenio Democrático. O 27 de marzo de 1872 consta que asinou o manifesto Electores del distrito de Vivero. No citado texto de Cantón Mayo (1995: 179-221) figuran datos sobre os irmáns Juan e Ventura Alvarado -fillos de Salustio Víctor-, na Escola Mercantil e Agrícola de Villablino. O primeiro casaría en 1907 con Luisa de la Vega Wetter, viúva de Augusto González de Linares e grande amiga de Carmen López Cortón, a muller de Cossío.

O conxunto da relacións de Galicia coa Fundación Sierra-Pambley, un traballo pendente, é fundamental para analizar a derivación cara o agro galego (industria leiteira dende Villablino, posta en marcha doutras industrias cárnicas e demais).

\section{REALIZACIÓNS EDUCATIVAS INSTITUCIONISTAS DO SÉCULO XX (1907-1936)}

\subsection{As accións da Xunta para Ampliación de Estudos}

En 1907, coa fundación da Junta para Ampliación de Estudios e Investigaciones Científicas (JAE), iníciase a terceira época da ILE. A Institución Libre non vai quedar reducida tan só a unha experiencia pedagóxica, senón que a súa influencia abarcará campos como o da investigación científica, a cultura artística, a preparación para a política, etc.

A JAE, como organismo que xa era do Estado, respondía ao sentido de intercambios con Europa propugnado pola ILE. Foi creada por R.D. de 11 de xaneiro de 1907 (Gaceta do 18 de xaneiro), sendo ministro Amalio Gimeno, e aproveitando unha conxuntura de política liberal no goberno de Vega de Armijo.

A composición orixinaria da JAE revela o influxo que nela posuía a ILE. Estaba composta dun presidente, dous vicepresidentes, 18 vogais e un secretario. Nas Actas de constitución figuran: Santiago Ramón y Cajal (presidente), Adolfo Álvarez Buylla, Gumersindo de Azcárate, Ignacio Bolívar, Julián Calleja, José Casares Gil, Joaquín Costa, José Echegaray, Victoriano Fernández Ascarza, José Fernández Jiménez, José Marvá, Marcelino Menéndez Pelayo, Ramón Menéndez Pidal, Julián Rivera Tarragó, José Rodríguez Carracido, Alejandro Sanmartín Satrústegui, Vicente Santamaría de Paredes, Luis Simarro, Joaquín Sorolla, Leonardo Torres Quevedo, Eduardo Vincenti Reguera e José Castillejo Duarte (secretario). En 1910 constan Amalio Gimeno e Eduardo Hinojosa, en lugar de Joaquín Costa e Alejandro Sanmartín. Á morte de José Rodríguez Carracido (1925), o posto vacante é ocupado por María de Maeztu, a única muller que desempeñou un posto de vogal na JAE (Vázquez Ramil, 2012).

O Regulamento da JAE data do 16 de xuño de 1907. A actividade máis destacada da Xunta foi o envío dos pensionados ao estranxeiro, do que tamén se beneficiou en boa medida Galicia (Porto Ucha e Iglesias Salvado, 2010: 731-757). Ao rematar o ano 1907, a JAE atravesou un período crítico, quedando case sen actividade, ao poñerse en cuestión a súa autonomía nos asuntos técnicos 
e pedagóxicos e a capacidade de elección de membros en caso de vacantes3. O ataque partiu tamén da mesma Universidade, que creu invadidas facultades que consideraba propias, como as referidas a pensións.

Baixo a influencia da JAE, e a partir de 1910, grazasao goberno liberal de Canalejas no que era ministro Instrución Pública Julio Burell, fóronse creando unha serie de institucións de radical importancia para a modernización cultural do país, tales como:

a) Centro de Estudos Históricos (R.D. do 18 de marzo de 1910), coas seccións de Filoloxía, Arqueoloxía, Arte, Dereito, Historia, Filosofía árabe, Institucións árabes, Filosofía Contemporánea, Estudos Semíticos, e Cursos para estranxeiros. A dirección estivo a cargo de Ramón Menéndez Pidal, e cada sección tiña, á súa vez, o seu director ou responsable.

b) Instituto Nacional de Ciencias Físico-Naturais (R.D. do 27 de maio de 1910). Director: Santiago Ramón y Cajal. No seu seo foron xurdindo dende os primeiros momentos outros establecementos: Laboratorio de Investigacións Biolóxicas e Físicas, Traballos de Ciencias Naturais, Estación Alpina de Bioloxía do Guadarrama, Laboratorio de Histoloxía e Histopatoloxía, Instituto Cajal, Comisión de Investigacións Paleontolóxicas e Prehistóricas, Laboratorio e Seminario Matemático, Laboratorio de Fisioloxía Xeral e Laboratorio de Bacterioloxía e Inmunidade.

c) Residencia de Estudantes (1910)

d) Residencia de Señoritas (1915)

e) Instituto-Escola (1918)

f) Misión Biolóxica de Galicia (1920)

g) Escola de Párvulos de Simancas (1933)

h) Varias cátedras no estranxeiro

Neste apartado imos prestar atención aos «laboratorios de provincias» da JAE, coa creación da Misión Biolóxica de Galicia, Residencia de Estudantes, Residencia de Señoritas eInstituto-Escola.

\subsection{A JAE e os «laboratorios en provincias»}

En 1920 a JAE tomou a decisión de establecer «laboratorios en provincias» nos lugares da xeografía española que aportaran axuda económica e facilidades para esta experiencia (JAE, 1922: 221-222). De aí a súa cooperación coas iniciativas locais, das que «la respuesta más entusiasta y eficaz fue la de Galicia» (JAE, 1929: 173).

3 Ao pouco de crearse a JAE, o 25 de xaneiro de 1907 faixe cargo do Ministerio de Instrución Pública Faustino Rodríguez Sampedro, no goberno do conservador Antonio Maura; manterase no cargo ata o 21 de outubro de 1909, cando é sustituido por Antonio Barroso Castillo nun goberno liberal de Segismundo Moret, moi próximo á ILE. 
Se a Misión Biolóxica se creou en Galicia cando a Xunta manifestou a súa vontade descentralizadora foi grazas ao gran mecenas galego Juan López Suárez (O Saviñao, Lugo, 1884 - Madrid, 1970), casado con Mariana Castillejo, irmá do secretario da Xunta, José Castillejo. Ligada así mesmo ás orixes da Misión Biolóxica está a figura de Cruz Gallástegui Unamuno (Vergara, Guipúzcoa 1891 - Pazo de Gandarón, Pontevedra 1960). Gallástegui estudara en Alemania, na Real Escola Superior de Agricultura de Hohenhein, preto de Stuttgart, de 1910 a 1914. Alí coñeceu a Julio López Suárez e máis tarde, en Lamaquebrada, cerca de Escairón (Lugo), a finca que tiña o seu irmán Juan. O Museo de Pontevedra conserva o importante Legado López Suárez - Castillejo.

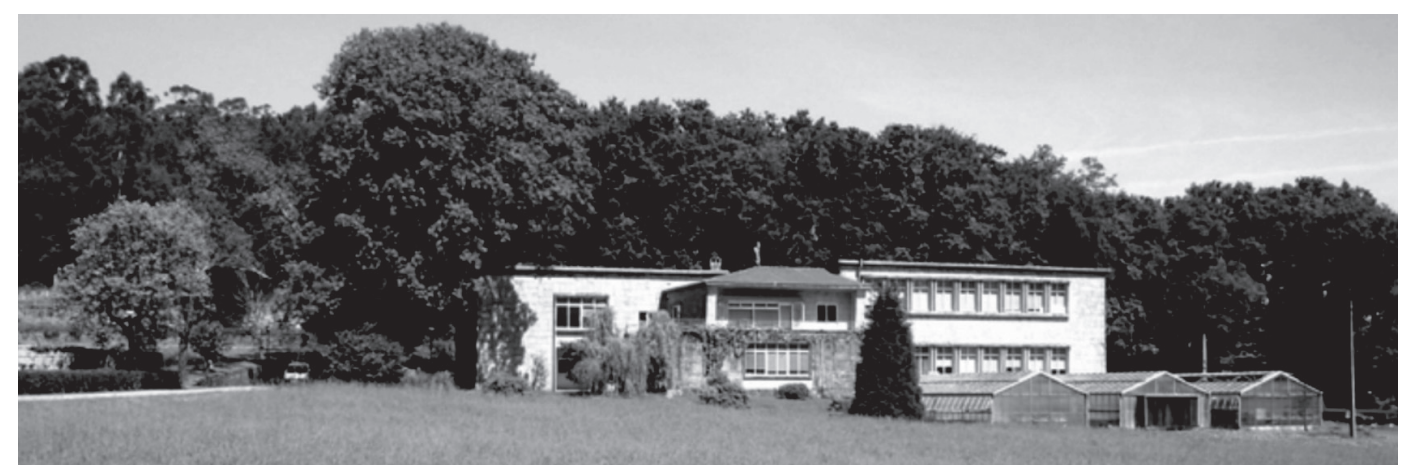

Figura 2. Misión Biolóxica de Galicia, no Pazo de Gandarón (Salcedo, Pontevedra). Fonte: http://www.jae2010.csic. es/centros 18.php

Non imos estendernos na descrición dos distintos lugares polos que pasou a Misión Biolóxica dende 1921 ata a guerra civil, tema xa tratado con anterioridade (Porto Ucha, 2005: 237-268): locais da Escola de Veterinaria e instalación provisional no edificio de San Clemente (Santiago de Compostela); terreos de «La Tablada», de Campolongo e Pazo de Gandarón, en Salcedo (Pontevedra). Creáronse tamén sucursais, como a herdade «Miraflores», situada na parroquia de San Pedro de Sárdoma (Vigo), cunha extensión de sete hectáreas e diversas parcelas de terreo nos arredores de Salcedo, a «Balada», dunha hectárea de extensión, e a «Boreira», de 40 áreas. Ademais destes predios, utilizáronse en diversos lugares de Galicia parcelas pertencentes a labradores, nas que se realizaron distintos ensaios. A Misión poñía a semente e o abono mineral e un capataz para dirixir a sementeira e a recolección. Fixéronse tamén ensaios en localidades de terreo e clima diferente dentro de Galicia: Cerceda e Ordes (A Coruña); Palas de Rei, Parga e Viveiro (Lugo), Xinzo de Limia (Ourense) e Lalín (Pontevedra), Debemos sinalar que a Misión ampliou o seu campo de investigación a outras zonas da xeografía española (como o Coto de Castilleja, na provincia de Valladolid, propiedade dos Varela Radío).

Os dous problemas que a Misión investigou foron a mellora xenética do millo híbrido, con vistas a acadar maiores producións unitarias de dito cereal en Galicia, e a enfermidade do castiñeiro (a chamada «tinta»). E así, realizáronse estudos sobre o virus na pataca, colaborando na rexenera- 
ción deste tubérculo. Prestóuselles tamén atención á remolacha e ás árbores froiteiras. Outro dos campos de estudo foi o porco dentro da economía galega, do que se encargou o enxeñeiro agrónomo Miguel Odriozola Pietas, pai da xenética animal en España. Traballouse ademais nas especies do xénero brassica (nabizas, grelos, coles forraxeiras, repolos), e nas leguminosas, as xudías verdes, entre outras (Porto Ucha, 2007).

De 1935 consérvase no Centro de Salcedo e tamén no Arquivo Histórico da Universidade de Santiago a Memoria referente ao funcionamento da Misión Biolóxica, tanto no que afectaba á parte económica como á eficacia dos traballos que levaba a efecto, formulada por Marcelino de Arana y Franco, representante da Dirección Xeral de Agricultura na Comisión de Vixilancia de dito Centro, que serviu de base para as actuacións posteriores. A guerra civil supuxo unha rotura co período anterior, aínda que a Misión Biolóxica, tras os momentos de incerteza producidos pola inestabilidade de contenda de 1936, iniciou unha nova andadura histórica, que continúa ata hoxe.

\subsection{A Residencia de Estudantes}

A Residencia de Estudantes de Madrid abriu as súas portas en 1910, sendo ministro de Instrución Pública Álvaro de Figueroa, Conde de Romanones. O R. D. de 6 de maio de 1910 (Gaceta do 8 de maio) sinalaba a súa creación. Alberto Jiménez Fraud foi director da Residencia de Estudantes ata 1936 (Sáenz de la Calzada, 1986).

En principio, a Residencia quedou instalada nuns edificios arrendados na rúa Fortuny, esquina con Rafael Calvo. Grazas as xestións de Sorolla, aos poucos meses da apertura, Alfonso XIII visitou os locais da Residencia, acompañado do Ministro de Instrución Pública, Amós Salvador, e da plana maior da JAE, con Cajal á cabeza e o Padroado da Residencia, presidido por Menéndez Pidal, que fixo os honores ao monarca. Giner de los Ríos non estaba presente, inda que, rematada a visita real, estreitaba na Castellana a man de Jiménez Fraud e lle expresaba: «criatura, qué responsabilidad» (Gómez Molleda, 1966: 489).

En 1915 a Residencia de Estudantes trasladouse aos Altos do Hipódromo («Cerro del Viento» ou «Colina de los Chopos», en poética denominación de Juan Ramón Jiménez), mentres os hoteis iniciais eran destinados á Residencia de Señoritas, que, cun espírito análogo á de homes, dependendo tamén da JAE, se puxo en marcha, con María de Maeztu Withney á fronte. Alberto Jiménez Fraud (casado con Natalia Cossío López, de ascendencia galega) foi proposto por Francisco Giner, que o chamou persoalmente para exercer o cargo de Director da Residencia de Estudantes (Monterrubio Pérez, 2004: 412-416).

A Residencia de Estudantes aspiraba a educar mediante a vida comunitaria de profesores e discípulos, en liberdade e coa presenza dun ideal colectivo a realizar. Posuía instalacións cómodas con biblioteca, laboratorios e campos de deportes. O ambiente era sinxelo e de bo gusto. Admitíanse estudantes dende os 16 años, de Universidade e de escolas especiais, e tamén profesores e investigadores.

Ademais dos estudantes, aloxábanse na Residencia, nos seus desprazamentos a Madrid, figuras como Machado, Azorín, Maeztu e outros escritores mozos. A lista sería ampla: García Lorca, 
Alberti, Salinas, Guillén, Zulueta, Morente, Américo Castro, Sánchez Albornoz, Madariaga, Pérez de Ayala, etc. Un dos persoeiros que entrou en contacto coa Residencia dende o primeiro momento foi Ortega e Gasset, que colaborou con disertacións e conferencias. Dos estranxeiros, foron hóspedes da Residencia, entre outros, Einstein, Bergson, Freud, Valery e Mme. Curie, se ben, dado que a Residencia de Estudantes viña integrando como «grupo femenino» á Residencia de Señoritas, as mulleres aloxáronse frecuentemente no segundo centro (caso de Victoria Ocampo ou Gabriela Mistral, entre as mais coñecidas).

Alberto Jiménez Fraud, en Historia de la Universidad Española (1971) dá conta de todas estas actividades e publicacións da Residencia, entre elas as relacionadas coa música e con Galicia e Asturias, as «Treinta canciones de Lope de Vega», do musicólogo, folclorista e compositor galego Jesús Bal y Gay, e as «Cuarenta canciones españolas» harmonizadas polo asturiano Eduardo Martínez Torner, quen «llegó allí por mediación de la Junta para Ampliación de Estudios que le encargó la clasificación y el estudio del Romancero Popular de España junto con su maestro Menéndez Pidal» (Sáenz de la Calzada, 1986: 115). Produto da súa exploración sobre a música, canto e bailes populares, levada a cabo a través da Comisión de Estudos en Galicia (dependente tamén da JAE), Martínez Torner e Bal y Gay deron na Residencia de Estudantes unha conferencia ilustrada coas primicias das súas investigacións sobre a misión folclórico-musical en busca de romances e cancións populares (JAE, 1931: 295-296). O traballo de ambos os dous sobre o folclore musical da rexión continuou nos anos 1933 e 1934 (JAE, 1935: 284 e ss.).

Baixo a inspiración do modelo da Residencia de Estudantes de Madrid, foron xurdindo outras iniciativas polo territorio español, entre elas a Residencia de Estudantes de Santiago (Porto Ucha, 1986: 309-314).

Coa traxedia do verán de 1936, a Residencia quedou convertida en hospital de guerra. Logo veu un tempo en que a Residencia de Estudantes se converte no Colexio Maior «Ximénez de Cisneros» e parte das súas dependencias son ocupadas polo Instituto «Ramiro de Maeztu». Pero iso xa corresponde á época do franquismo, a partir de finais da guerra civil.

\subsection{A Residencia de Señoritas}

Por R.O. do 11 de agosto de 1913 autorizouse a construción de edificios residenciais nos citados terreos dos Altos do Hipódromo propiedade do Ministerio de Instrución Pública. Os novos edificios da Residencia de Estudantes inauguráronse en outubro de 1915, acollendo entón a cen estudantes. Desta maneira, os hoteliños de Fortuny quedaron baleiros ea JAE decidiu aproveitalos para albergar un grupo de nenos do Instituto-Escola e outro de señoritas. E así, no mesmo mes de outubro de 1915 as casas números 28 e 30 da rúa Fortuny foron ocupadas por un grupo de mozas con trinta prazas, que se convertería no Grupo Feminino da Residencia de Estudantes, tamén coñecido por Residencia de Señoritas. Ese nome-como apunta agudamente Cacho Viu-, «que hoy nos hace sonreír, denota por sí solo la barrera que aún separaba a la mujer de su integración plena en la vida profesional» (Cacho Viu, 1986: 16). Como directora, foi elixida pola JAE María de Maeztu y Whitney, previa recomendación de José Ortega y Gasset (Vázquez Ramil, 2012). 
Ao pouco tempo, a Residencia de Señoritas veu superada a súa capacidade pola crecente demanda de prazas. Impúñase unha ampliación. A Residencia contará entón coa colaboración dunha institución estadounidense situada nas súas proximidades e centrada tamén na educación da muller, o International Institute for Girls in Spain, máis coñecido como Instituto Internacional (Zulueta, 1984). O Instituto Internacional cedeu parte dos seus edificios á Residencia de Señoritas e, sobre todo, ofreceu o labor asesor e docente de profesoras americanas que se encargaron de materias novas en España como inglés, biblioteconomía, deportes, ximnasia rítmica e clases prácticas de ciencias e química.

Nos seus inicios, a JAE presenta a Residencia de Señoritas como centro destinado ás rapazas que seguían os seus estudos ou preparaban o ingreso nas Facultades universitarias, Escola Superior do Maxisterio, Conservatorio Nacional de Música, Escola Normal, Escola do Fogar e Profesional da Muller ou outros centros de ensinanza, e ás que privadamente se dedicaran ao estudo en bibliotecas, laboratorios, arquivos, clínicas, etc. (JAE, 1916: 300).

Existía certa rivalidade coa Institución Teresiana, fundada polo Padre Poveda, que en marzo de 1914 abrira en Madrid unha residencia para alumnas de maxisterio. O control do maxisterio, da inspección primaria e do profesorado de Escolas Normais era terreo rifado entre a ILE e as súas derivacións (a JAE) e determinadas empresas da Igrexa católica. O primeiro afán da Residencia de Señoritas foi, por tanto, contribuír á formación de «formadoras», captando para elo a alumnas da Escola Superior do Maxisterio. Conséguese grazas á dedicación de María de Maeztu, que organizou un completo programa de formación preparatoria e complementaria. En 1922 a propia María de Maeztu confesa a Alberto Jiménez Fraud, director da Residencia de Estudantes, a súa satisfacción polo éxito acadado (ARSM: Minuta de carta, Caixa 56):

No sé si le he dicho a usted que hemos tenido un éxito completo en la Escuela Superior del Magisterio: han ingresado nada menos que once muchachas; de la Academia Teresiana, a pesar de los artículos panegíricos que nos hacen, han ingresado dos. Por primera vez en la vida me convenzo de que la Filosofía tiene un valor cotizable.

Para acoller ás estudantes de carreira superior, no curso 1920-21 a Residencia estrutúrase en dous grupos o secciones: a sección xeral dirixida por María de Maeztu e domiciliada en Fortuny 30 e a sección especial universitaria conectada co International Institute for Girls in Spain e dirixida pola profesora de Smith College Mary Louise Foster. Este acordo entre o Instituto Internacional e a Residencia de Señoritas permitiu organizar un modelo de centro residencial-educativo que seguía de cerca as pautas dos colleges femininos estadounidenses, os cales mantiveron estreitos contactos coa Residencia de Señoritas dende 1919 (Vázquez Ramil, 2012: 259 e ss.).

María de Maeztu expresou en 1922 a súa intención de ampliar a Residencia, contando coas achegas materiais e humanas do Instituto Internacional, moi interesado en manter un centro educativo para mulleres, similar aos colleges estadounidenses. A JAE interveu nas negociacións de forma un tanto ambigua, pois aspiraba a conseguir o apoio material da institución americana para o Instituto-Escola, en detrimento da Residencia de Señoritas. Tras arduas negociacións e esgotadoras viaxes a Estados Unidos, María de Maeztu logrou que o Instituto Internacional vendese ao Estado español un dos seus edificios, o hoteliño rodeado de xardín da rúa de Fortuny 53, en condicións 
económicas moi vantaxosas, pero coa condición inescusable de que se dedicase á educación superior da muller española. Así o di nunha cláusula da escritura de venta, outorgada ante notario en 1924 (ARSM. Caja 6, carpeta 9).

Entre as estudantes universitarias, foron maioría as residentes matriculadas en Farmacia, carreira que non existía en todos os distritos universitarios e que se consideraba especialmente apta para a muller. A continuación, seguíanlle as estudantes de Filosofía e Letras, Medicina, Odontoloxía, Ciencias e Dereito. Xa nos anos trinta encontramos as primeiras estudantes de Arquitectura ou das moi minoritarias carreiras técnicas.

Para as universitarias a Residencia ofrece, a partir de 1928, clases gratuítas de Inglés, Francés, Alemán, Física e Química, Química inorgánica e Análise químico, Mineraloxía, Botánica, Bioloxía e Zooloxía, Farmacia práctica, Anatomía, Histoloxía, Dereito político e administrativo, e Hebreo. En 1929 destaca un pequeno grupo de alumnas de bacharelato. Entre as estudantes de Música, sempre presentes aínda que non de forma destacada, foron maioría as de Piano, seguidas polas de Canto.

A finais dos anos 20 a idea de María de Maeztu era converter a Residencia nun centro de carácter universitario para mulleres; así o expresaba María de Maeztu nunha carta dirixida a Ramón y Cajal (ARSM, 1928, Caixa 9). O ambicioso proxecto non prosperou.

Durante a Segunda República a Residencia continuou crecendo, pero os sucesivos ministros de Instrución Pública centraron os seus esforzos en abrir novas escolas e en contratar mestres. María de Maeztu, coa súa habitual perspicacia, así o ve e en 1934 reorienta a obra, abríndoa a todas aquelas mulleres que desexasen ampliar a súa cultura xeral ou adquirir uns coñecementos útiles para gañarse a vida.

A Residencia de Señoritas non foi allea a outras actividades culturais como a súa homónima masculina: veladas musicais, conferencias, sesións teatrais e actos sociais con importantes persoeiros aos que as residentes tiñan ocasión de coñecer de certa.

Pola Residencia de Señoritas pasaron moitas galegas. Entre elas, Rita Fernández Queimadelos, natural da Cañiza (Pontevedra), a primeira muller arquitecta que exerceu en España; Olimpia Valencia López, médica, natural de Ourense, que exerceu como xinecóloga en Vigo; Sofía Novoa Ortiz, pianista, que colaborou con María de Maeztu na xestión da Residencia; Ángeles Alvariño González, de Ferrol, bióloga e oceanógrafa en Estados Unidos; María Antonina Sanjurjo Aranaz, de Vigo, pioneira do hockey feminino en Galicia; Ángeles Pardo Celada, de Becerreá (Lugo), que se especializou en xinecoloxía e puericultura; Raquel Lesteiro López, de Pontevedra, que traballou con Américo Castro no Centro de Estudos Históricos; Carmen Pardo Losada, de Ourense, que chegou a ser directora da Escola Normal de Mestras de Lugo, entre moitísimas outras.

\subsection{O Instituto-Escola}

O Instituto-Escola de Madrid foi creado, con carácter provisional, como ensaio pedagóxico para a reforma da segunda ensinanza, por R.D. do 10 de maio de 1918, sendo Ministro de Instrución Pública o liberal Santiago Alba (Palacios Bañuelos, 1988). Tratábase de buscar solución aos problemas que arrastraba a segunda ensinanza. O centro, na súa organización, orientación xeral e 
inspección quedaba baixo a dirección da JAE, co fin de experimentar novos métodos de educación e sistemas prácticos para a formación do persoal docente (JAE, 1925).

Seguindo as ideas defendidas pola Institución Libre de Enseñanza, o Instituto-Escola uniu a ensinanza primaria e a secundaria, tratando de facer de ambas un solo proceso de formación do alumnado, con iguais ideais, pero coa gradual diferenciación de métodos e contido. Pouco despois da creación do Instituto-Escola, a petición das familias, ampliouse cunha nova sección de párvulos. Había estudos comúns e obrigatorios ata os quince anos, e unha posibilidade de especialización nos dous últimos cursos (15-16 e 16-17 años). O avance nos estudos ía acompañado da promoción duns graos a outros.

O Instituto-Escola non dispuxo de director, senón dun profesor delegado diante da JAE. Sinala Martínez Alfaro (2009: 44):

Hasta 1925, José Castillejo, el secretario de la JAE, fue presumiblemente el encargado de supervisar el funcionamiento del Instituto-Escuela (...) A partir de 1925, el Instituto-Escuela contó con un patronato específico, integrado por los siguientes miembros de la JAE: Ignacio Bolívar, Ramón Menéndez Pidal, José Ortega y Gasset, Blas Cabrera, José G. Álvarez Ude y María de Maeztu.

A partir de 1933 ampliouse o número de membros do Padroado, coa incorporación dos representantes da xunta de profesores, dos pais e de antigos alumnos. Na secretaría do Instituto-Escola estivo Victoria Kent, á que se lle concedeu a excedencia en 1932, ao ser nomeada Directora Xeral de Prisións. Victoria Kent estivo vinculada ao centro dende a súa creación, sendo estudante de Dereito e residente na Residencia de Señoritas, onde colaboraba con María de Maeztu. O Instituto-Escola contou tamén cun servizo de comedor e cunha biblioteca.

As ensinanzas, segundo o art. $7^{\circ}$ do referido decreto de creación,

(...) estarán a cargo de catedráticos numerarios o auxiliares de Institutos generales y técnicos y de aspirantes al Magisterio secundario. A la Sección preparatoria podrán ser llamados maestros superiores. Las enseñanzas de idiomas vivos podrán encomendarse a súbditos extranjeros. Para dirigir la formación del Profesorado secundario podrá la Junta proponer el nombramiento de profesores especiales.

Os catedráticos do Instituto-Escola, procedentes do corpo de Catedráticos de instituto en comisión de servizos e cunha remuneración complementaria, «eran designados por el Ministerio de Instrucción Pública, a propuesta unipersonal de la Junta para Ampliación de estudios e investigaciones científicas, a medida que los vaya necesitando por el sucesivo establecimiento de los grados»» $\left(\right.$ art. $8^{\circ}$ ). O profesorado beneficiouse das pensións a Europa para coñecer innovacións pedagóxicas que despois aplicaba nas clases. Ademais de intercambios a través das colonias escolares (A JAE creou unha colonia de intercambio na Granxa de San Ildefonso, Segovia), houbo tamén intercambios educativos co alumnado doutros países, de Francia, Alemaña e Inglaterra.

Por R.O. de 10 de xullo de 1918, foi aprobado o Regulamento do Instituto-Escola, que contemplaba o plano de estudos (Porto Ucha, 2004). As ensinanzas quedaban distribuídas en nove graos (tres da Sección Preparatoria e seis da Sección Secundaria). A Sección Preparatoria estaba destinada a alumnos e alumnas de idades comprendidas entre os oito e os dez anos cumpridos (8-9, 9-10, 1011 anos), podendo ser admitidos ou permanecer nela alumnado doutras idades en consideración á 
súa precocidade ou ao seu retraso. Nos graos da Sección Secundaria, as idades de admisión eran de once anos a dezaseis cumpridos (11-12, 12-13, 13-14, 14-15, 15-16, 16-17 anos); excepcionalmente podían figurar nela alumnos adiantados con dez anos cumpridos. do R.D.,

O Regulamento concreta as materias a cursar en cada grao. Segundo o apartado c) do art. $2^{\circ}$

Las enseñanzas abarcarán, por lo menos, las materias que constituyen actualmente el plan de estudios de los Institutos de segunda enseñanza; pero la Junta, previa propuesta al Ministerio, podrá establecer la división de bachillerato clásico y de Ciencias, en cuyo caso, para los alumnos de este último, el Latín, el Griego y las enseñanzas literarias podrán sustituirse, total o parcialmente, por Lenguas vivas y Ciencias. Para la enseñanza de Religión se observarán las disposiciones vigentes.

Ademais das materias, inclúense xogos, excursións e visitas a Museos e lugares de interese. Había tamén traballos de laboratorio e de taller en madeira e metal (substituíbles para as rapazas por labores e economía doméstica), debuxo, fotografía e modelado.

A elección de materias para formar o plano de estudos de cada alumno/a nos últimos dous graos facíase por acordo entre a xunta de profesores e as familias, tendo en conta o propósito destas respecto ao porvir dos seus fillos, a vocación e aptitude de cada alumno e o nivel de preparación que conseguira nos seus anos anteriores de estudos. O número de alumnos nas clases non pasaría de 30. Nas prácticas de taller e laboratorio e traballos manuais, procuraríase que non excedesen de 15.

Nos artigos $7^{\circ}, 8^{\circ}$ e $9^{\circ}$ do Regulamento sinálanse os fins, medios e principios que inspiran os métodos de ensinanza. Como finalidades, as ensinanzas deberían desenvolver, mediante un adecuado exercicio, as facultades mentais, o poder de observación e comprensión, a firmeza de xuízo, a orixinalidade, a pluralidade de intereses e as aptitudes para a acción, entre outras; tamén a adquisición, de acordo coa idade, dos coñecementos de cultura xeral e a preparación para os estudos superiores. Como principais medios de ensinanza, sinálase a acción, o estudo directo da natureza ou das cousas, o diálogo entre profesor/a e alumno/a e a exposición maxistral; na sección elemental acentuaríase moi especialmente a correlación entre a actividade de pensar e a actividade creadora e executora. Os métodos inspirábanse en principios como o de espertar a curiosidade cara as cousas e centrar nela o proceso didáctico; evitar o interese artificial e estimular o esforzo a partir da motivación interna (curiosidade, instinto de actividade creadora, conciencia moral e satisfacción por acadar un fin).

En definitiva, tratábase dun centro cun programa de estudos de carácter integral, que apostaba polo desenvolvemento cíclico, segundo a propia evolución persoal do alumnado, e no que non había un sistema ríxido de exames. Hai novas materias como as linguas modernas, as ensinanzas artísticas e traballos manuais como medios eficaces auxiliares para o desenvolvemento mental. Sendo fin primordial a formación do carácter, a vida normal da escola debería desenvolverse nun ambiente de liberdade e de mutua confianza, de claro selo institucionista. As faltas eran corrixidas mediante a amoestación privada. O profesorado levaba un caderno de clase, participando en tarefas diversas.

No Instituto-Escola figuraba tamén a formación de aspirantes ao profesorado secundario. Segundo o art. 10 do referido R.D. 
Para ser admitido a la Escuela como aspirante al Magisterio secundario se requerirá ser español, mayor de diez y siete años y haber hecho o estar siguiendo estudios universitarios en las Facultades de Ciencias o Filosofía y Letras. La Junta determinará cualesquiera otras condiciones que considere exigibles, y hará las admisiones comunicándolo al Ministerio.

A formación de ditos aspirantes (art. 11) ensaiaríase combinando, simultánea ou sucesivamente:

Los estudios universitarios.

Las prácticas docentes en la Escuela.

La crítica, lectura, trabajos personales y experimentales de seminario pedagógico.

Los estudios y prácticas complementarios en centros extranjeros.

Estes aspirantes ao Maxisterio secundario poderían ser encargados de clases e correccións de exercicios e cooperaban na vixilancia, xogos e excursións, etc. Foi esta, a formación dos denominados «aspirantes», unha importante novidade, pola que se lle encomendaba ao Instituto-Escola a contribución á formación profesional do profesorado de secundaria.

Como xa apuntamos anteriormente, o Instituto-Escola comezou as súas actividades en 1918, no número 8 da rúa Miguel Ángel de Madrid, nuns locais alugados ao Instituto Internacional. No curso 1918-19 foron un total de 87 alumnos (mixto) repartidos en 3 grupos na secundaria; no curso seguinte, 1919-20, acadaron 130, repartidos en 5 grupos, correspondentes, co ano anterior, aos dous primeiros cursos de bacharelato. Mentres na ensinanza oficial o número de alumnos por aula podía ser superior a 100 (Romanones en 1901 limitárao a 150), no Instituto-Escola, segundo o art. $6^{\circ}$ do Regulamento, tal como xa sinalamos, tiñan 30 alumnos por aula y 15 en prácticas de taller e laboratorios.

No curso 1920-21, debido a que o Instituto Internacional non podía admitir nos seus locais aos alumnos varóns de secundaria do Instituto-Escola, a JAE decidiu trasladar aos alumnos ao pavillón número 5 da Residencia de Estudiantes (Martínez Alfaro, 2009: 67 e ss.) nos Altos del Hipódromo (104 alumnos no curso 1920-21), mentres as alumnas do Instituto-Escola e da Residencia feminina continuaron no Instituto-Internacional (80 alumnas no curso 1920-21). A autora citada, Encarnación Martínez Alfaro (2009: 237), preséntanos a evolución cuantitativa do alumnado no tempo (1918-19 a 1934-35). Oscila entre preto dos 200 e máis de 300 alumnos/as por sección, repartidos por grupos. Do conxunto do alumnado, «5 de Galicia, de todas las provincias (2 de La Coruña»).

A JAE mercou en 1921 ao Padroado Nuestra Señora de Atocha un terreo no lado sur do Parque do Retiro coa finalidade de dispor dun edificio propio para o Instituto-Escola. En 1922 encargóuselle a redacción do proxecto ao arquitecto Francisco Javier Luque (Guerrero, 2007). Sen embargo, por limitacións orzamentarias, construíuse un solo pavillón, o terceiro dos catro previstos, que o Instituto-Escola destinou a partir de 1928 á ensinanza secundaria. Ao final, nun proceso que a autora citada analiza detidamente, son os alumnos os que ocupan esa Sección Retiro, mentres as alumnas instálanse na Sección Hipódromo. É dicir, alumnos e alumnas estudaban no Instituto-Escola en edificios separados, primeiro repartidos entre as Seccións de Hipódromo (alumnos) e Miguel Ángel (alumnas), e logo nas Seccións do Retiro (alumnos) e Hipódromo (alumnas), agás nos cursos 
1918-19 e 1919-20 (no edificio de Miguel Ángel) nos que a ensinanza foi mixta (Ontañón e Vázquez de Castro, 2006). A coeducación implantaríase máis tarde, concretamente coa chegada da Segunda República, no curso 1931-32.

De acordo co preceptuado, a JAE emitía en 1925 un Informe sobre o funcionamento do Instituto-Escola, xunto co R.D. de creación, o Regulamento, as Instrucións e consellos para os aspirantes ao Maxisterio secundario, as ensinanzas e métodos, cunha nota preliminar da Sección Preparatoria, a cargo de María de Maeztu, publicados baixo o citado título de El Instituto-Escuela de Segunda Enseñanza de Madrid. Organización, métodos y resultados (JAE, 1925). Como consecuencia, no curso 1926-1927 introducíronse modificacións no primeiro curso de secundaria para garantir a continuidade entre a ensinanza primaria e a secundaria.

Por R.D. do 1 de marzo de 1930, o Instituto-Escola adquiriu carácter permanente e o profesorado en comisión de servizos pasou a definitivo. No curso 1933-1934 experimentou unha importante reorganización, coa unificación docente, económica e administrativa das seccións de primaria (preparatoria) e secundaria. Ata entón, a sección primaria dispoñía dunha organización autónoma, condicionada polas contribucións das familias, mentres que a secundaria dependía da JAE, aínda que recibía tamén remuneracións das familias. A partir de aquí, o Instituto-Escola quedou dividido en catro seccións: $1^{\mathrm{a}}$, párvulos, cuxo edificio no Hipódromo corresponde ao período 1933-35 (Guerrero, 2009: 378-405); 2a , primaria, $3^{\mathrm{a}}$, bacharelato da Sección Pinar (Hipódromo) e 4 ${ }^{\mathrm{a}}$, bacharelato da Sección Retiro (Martínez Alfaro, 2009: 222). A reorganización afectou tamén á composición do Padroado e á Xunta de profesores de cada sección, que constituían o claustro xeral do Instituto-Escola. A JAE nomeou a Jimena Menéndez Pidal directora da Sección Párvulos, mentres que a Sección Primaria continuaba baixo a dirección de María de Maeztu.

Entre o profesorado que pasou polo Instituto-Escola, cabe destacar a nivel galego ao catedrático de Ciencias Naturais e botánico Luis Crespí Jaume (1889-1963). Luis Crespí era fillo do farmacéutico e botánico mallorquino Antonio Crespí Mas, que foi catedrático de Agricultura no Instituto Xeral e Técnico de Pontevedra. Nacido en Madrid en 1889, Luis Crespí estudou Ciencias Naturais na Universidade de Santiago de Compostela, ampliando estudos no Museo Nacional de Ciencias Naturais. En 1916 gañou a cátedra de Agricultura do Instituto de Lugo, pasando tamén polo de Pontevedra, inda que continuou o seu proceso de formación como bolseiro da JAE. Foi catedrático de Agricultura no Instituto-Escola entre 1918 e 1936. En 1922 foi nomeado Catedrático Numerario do Instituto Xeral e Técnico de Guadalajara, se ben continuou no Instituto-Escola, no que obtivo o nomeamento definitivo como Catedrático en abril de 1930, posto que compatibilizou co de director do Laboratorio de Ecoloxía do Museo Nacional de Ciencias Naturais ata 1936. Entre 1936 e 1939 continuou dando clases nos Institutos «Pérez Galdós»e «San Isidro» de Madrid ata 1939.

Trala guerra, Luis Crespí foi inhabilitado para a docencia durante nada menos que 14 anos. Pertencía a Izquierda Republicana. Tivo que traballar como administrativo nos Laboratorios «Promesa» de Madrid, que elaboraban produtos medicinais. En 1954 foi reintegrado na súa cátedra, cando Joaquín Ruiz Giménez era Director Xeral de Ensinanzas Medias, exercendo a docencia no Instituto «San Isidro». Xubilou en 1959. Sen embargo, o labor investigador de Crespí veuse definitivamente interrompido en 1938 (Masip Hidalgo, 2011: 501-511). 
Na Memoria da JAE de 1918 e 1919, Crespí figura como profesor da 2a Sección Secundaria de Ciencias Naturais do Instituto-Escuela (JAE, 1920: 280). Como catedrático de Agricultura, gozou dunha pensión para visitar Francia, segundo R.O. de 3/9/1917 (JAE, 1918: 59) e R.O. de 12/1/1918 (JAE, 1920: 42-43), para estudar fisioloxía vexetal con Leclerc du Sablon e patoloxía agrícola. Posteriormente, por RR.OO. de 10/9 e 4/11/1924 foi a Portugal, por cuestiones técnicas, afondando no estudo dos liques e da ensinanza agrícola (JAE, 1927: 32-33).

No verán de 1927 a JAE organizou, a través da Comisión de Estudos en Galicia, unha misión de estudos, unha exploración naturalista e folclórica nos Ancares e montes do Invernadoiro e Queixa. A excursión foi realizada baixo a dirección de Luis Crespí Jaume. Iniciouse en Ponferrada, tomando parte, ademais, Luis Iglesias, auxiliar da Facultade de Ciencias da Universidade de Santiago, Gustavo Nieto Vallas, do Instituto de Ourense, e o profesor doutor Nicolás I. Vavilov, Director do Instituto de Agronomía Experimental e do Instituto de Botánica Aplicada á Mellora das Plantas da Universidade de Leningrado, que viña percorrendo en viaxe de estudos Asia, Etiopía, Abisinia e o sur de Europa. De Ponferrada dirixíronse a Vilafranca do Bierzo, continuando ata Piedrafita do Cebreiro e logo, seguiron pola estrada de Lugo a Becerreá, estudando a flora, a fauna e costumes destes apartados lugares de Galicia (Porto Ucha, 1986: 303-304).

Entre os denominados «profesores aspirantes» do Instituto-Escola, localizamos no curso 1927-28 a Raquel Lesteiro López, da especialidade de Lingua, bibliotecaria do Centro de Estudos Históricos, e a Pilar Lago Couceiro (curso 1929-30), así mesmo da especialidade de Lingua, profesora adxunta/funcionaria da Administración. Raquel Lesteiro estivo na Residencia de Señoritas no curso 1921-22. Fixo oposicións a Arquivos e tivo destino en Pontevedra, como Facultativa de Arquivos e Bibliotecas, no Arquivo Provincial (Vázquez Ramil, 2012: 415). Tamén colaborou no Instituto-Escola Manuel Pedreira Deibe, que era profesor auxiliar de Xeografía e Historia no Instituto Xeral e Técnico de A Coruña, e solicitou directamente a Castillejo traballar no novo centro mentres preparaba oposicións a cátedras, no curso 1921-22, sendo atendida a súa minuciosa e ben xustificada petición.

Entre o alumnado masculino, cabe citar a Enrique Vidal Abascal (curso 1930-31), da especialidade de Matemáticas. Vidal Abascal, sendo catedrático do Instituto de Pontevedra, foi presidente da Comisión Provincial de Depuración (D), sucedendo a Secundino Vilanova Rivas, tamén catedrático, nese cometido en 1940 (Porto Ucha, 2008: 59). Posteriormente foi catedrático da Universidade de Santiago de Compostela. Entre as alumnas galegas do Instituto-Escola debemos facer referencia a María Victoria Casares Pérez, filla de Santiago Casares Quiroga, que logo acadará fama como actriz no exilio francés co nome de María Casares.

A partir de comezos dos anos 30, foron aparecendo outros centros similares ao Instituto-Escola de Madrid. Un decreto de 9 de outubro de 1931, autorizaba á Generalitat de Cataluña a creación dun Instituto-Escola. Foi o seu primeiro director Josep Estalella i Graells, catedrático do Instituto de Girona e «uno de los profesores de primera hora en el Instituto-Escuela madrileño» (Delgado, 2000: 148), aínda que a súa estancia en Madrid foi breve (1919-1922). Outro Decreto de 2 de febreiro de 1932 creaba os Institutos-Escola de Valencia e Sevilla e, un ano despois, segundo Orde Ministerial do 17 de febreiro de 1933, o de Málaga. 
No modelo do Instituto-Escola apreciamos a fusión do ensino primario e secundario, sen rupturas «traumáticas», nun intento de converter a educación en un continuo dende os primeiros anos ata o punto onde permitiran as capacidades do alumnado. Como é sabido, o modelo foi tan abraiante como minoritario e prosperou onde había fondos suficientes e unha mentalidade aberta; o ensino oficial continuou facendo esforzos meritorios por estender as nocións elementais, poñendo énfase na creación de escolas e na contratación de mestres; o ensino privado tivo outras preocupacións, entre elas a defensa de posturas ideolóxicas enfrontadas, como durante a Segunda República; e logo impúxose durante moito tempo a ruptura, verdadeiramente «traumática» entre o ensino primario para todos, o secundario para menos, e o superior para uns poucos ata case a Lei Xeral de Educación de 1970.

\section{REFERENCIAS BIBLIOGRÁFICAS}

Cacho Viu, V. (1986). Prólogo. En M. Sáenz de la Calzada. La Residencia de Estudiantes (19101936). Madrid: C.S.I.C., pp. 11-22.

Cantón Mayo, I. (1995). La Fundación Sierra-Pambley. Una institución educativa leonesa. León: Secretariado de Publicaciones de la Universidad de León.

Capelán Rey, A. (1999). Contribucións a unha historia da Universidad Popular da Coruña. Sarmiento. Anuario Galego de Historia da Educación, 3, pp. 25-64.

Capitán Díaz, A. (1994). Historia de la Educación en España II. Pedagogía Contemporánea. Madrid: Dykinson.

Costa Rico, A. (1994). A Colonia Escolar Compostelana de 1893. Primeiro Centenario. Santiago: Consorcio de Santiago.

Costa Rico, A. e Benítez García, M.X. (1999). Marcelino Pedreira. Un mestre corunés baixo a influencia de Pestalozzi e da Escola Nova. Anuario Brigantino, n 22, pp. 221-236.

Cueva, J. de la y Montero, F. (Eds.) (2007). La secularización conflictiva. España (1898-1931). Madrid: Biblioteca Nueva.

Delgado, B. (2000). La Institución Libre de Enseñanza en Catalunya. Barcelona: Ariel.

Fernández Soria, J. M. (1985). Universidades populares. Historia de la Educación II. Diccionario de Ciencias de la Educación. Madrid: Anaya, pp. 366-67.

García del Dujo, A. (1985). Museo Pedagógico Nacional (1882-1941): Teoría educativa y desarrollo histórico. Salamanca: Ediciones Universidad de Salamanca, Instituto de Ciencias de la Educación.

Gómez Molleda, M.D. (1966): Los reformadores de la España contemporánea. Madrid: C.S.I.C. 1981 [reprodución en off-set da $1^{a}$ edición de 1966].

Guerrero, S. (2006). La Junta para Ampliación de Estudios y la arquitectura de su tiempo. BILE, 63-64, pp. 249-277.

Guerrero, S. (2009). Fortuna crítica y memoria física de las arquitecturas de la JAE después de 1939. En J. M. Sánchez Ron e J. García-Velasco (Eds.) (2010). 100 JAE. La Junta para Ampliación de Estudios e Investigaciones Cientificas en su Centenario, t. 2. Madrid: Fundación Francisco Giner de los Ríos - Publicaciones de la Residencia de Estudiantes, pp. 378-405.

Jiménez Fraud, A. (1971). Historia de la Universidad Española. Madrid: Alianza Editorial. 
Junta para Ampliación de Estudios e Investigaciones Científicas (1916). Memoria correspondiente a los años 1914 y 1915. Madrid: Imp. de Fortanet.

Junta para Ampliación de Estudios e Investigaciones Científicas (1918). Memoria correspondiente a los años 1916 y 1917. Madrid: Imp. de Fortanet.

Junta para Ampliación de Estudios e Investigaciones Científicas (1920). Memoria correspondiente a los años 1918 y 1919. Madrid: Imp. de Fortanet.

Junta para Ampliación de Estudios e Investigaciones Científicas (1922). Memoria correspondiente a los años 1920 y 1921 . Madrid: Imp. de Fortanet.

Junta para Ampliación de Estudios e Investigaciones Científicas (1925). Un Ensayo Pedagógico. El Instituto-Escuela de Segunda Enseñanza de Madrid. Organización, métodos, resultados. Madrid: Tip. de la «Revista de Archivos».

Junta para Ampliación de Estudios e Investigaciones Científicas (1927). Memoria correspondiente a los cursos 1924/25 y 1925/26. Madrid: Imp. de Fortanet.

Junta para Ampliación de Estudios e Investigaciones Científicas (1929). Memoria correspondiente a los cursos 1926-27 y 1927-28. Madrid: Imp. de Fortanet.

Junta para Ampliación de Estudios e Investigaciones Científicas (1931). Memoria correspondiente a los cursos 1928-29 y 1929-30. Madrid: Imp. de Fortanet.

Junta para Ampliación de Estudios e Investigaciones Científicas (1935). Memoria correspondiente a los cursos 1933 y 1934. Madrid: Imp. de Fortanet.

Jiménez Eguizábal, J. A. (1985). Extensión universitaria. Historia de la Educación II. Diccionario de Ciencias de la Educación. Madrid: Anaya, pp. 133-135.

Jiménez García, A. (2002). El Krausismo y la Institución Libre de Enseñanza. Madrid: Ediciones Pedagógicas.

López Contreras, J. (1986). La Fundación «Sierra-Pambley» y la Institución Libre de Enseñanza. En E. Huertas Vázquez, L. Sáenz de la Calzada e J. López Contreras. León y la Institución Libre de Enseñanza. León: Diputación Provincial de León, pp. 134-221.

Martínez Alfaro, E. (2009). Un laboratorio pedagógico de la Junta para Ampliación de Estudios. El Instituto-Escuela Sección Retiro de Madrid. Madrid: Biblioteca Nueva.

Masip Hidalgo, C. (2011). Luis Crespí Jaume, científico de la Junta para Ampliación de Estudios y catedrático de Agricultura del Instituto-Escuela. Arbor, vol. 187, mayo-junio, pp. 501-511. DOI: https://doi.org/10.3989/arbor.2011.749n3004

Mateo Díez, L. (1986). La fuente de la edad. Madrid: Alfaguara.

Monterrubio Pérez, A. (2004). Alberto Jiménez Fraud. Málaga, 1883 - Ginebra, 1964. En O. Negrín Fajardo (Dir.). Historia de la Educación en España. Autores, textos y documentos. Madrid: UNED, pp. 412-416.

Ontañón, E. e Vázquez de Castro, L. (2006). El Instituto-Escuela y sus edificios e instalaciones. BILE, 63-64, pp. 279-300.

Palacios Bañuelos, L. (1988). Instituto-Escuela. Historia de una renovación educativa. Madrid: MEC.

Pereira Domínguez, M. C. (1991). La obra socio-educativa realizada por la Caja de Ahorros Municipal de Vigo a través de las Colonias Escolares (1927-1983). Vigo: Galicia Editorial. 
Porto Ucha, A. S. (1986): La Institución Libre de Enseñanza en Galicia. Sada - A Coruña: Ediciós do Castro.

Porto Ucha, A. S. (1991). Institucións complementarias no contexto da escola primaria: As colonias escolares da Universidade de Santiago (1923-25). Adaxe, 7, pp. 83-96.

Porto Ucha, A. S. (2004). Decreto de creación del Instituto Escuela. 10 de mayo de 1918. En O. Negrín Fajardo (Dir.). Historia de la Educación en España. Autores, textos y documentos. Madrid: UNED, pp. 551-556.

Porto Ucha, A. S. (2005). La Institución Libre de Enseñanza y la renovación pedagógica en Galicia. Sada - A Coruña: Ediciós do Castro.

Porto Ucha, A. S. (2007). Los «laboratorios en provincias» de la JAE: La Misión Biológica de Galicia (1921-1936). XIV Coloquio Nacional de Historia de la Educación. Vol. 1, En F. Sánchez, J. Alejo et al. (Coords.) Relaciones internacionales en la Historia de la Educación. Junta para Ampliación de Estudios e Investigaciones Cientificas (907-2007). Cáceres: Universidad de Extremadura/ SEDHE, pp. 437-446.

Porto Ucha, A. S. (2008). Mestras e mestres pontevedreses depurados polo franquismo. Primeiras acción represivas e estudo por concellos no sur da provincia de Pontevedra. Ponteareas: Alén Miño.

Porto Ucha, A. S. (2014). O impulso do Museo Pedagóxico de Galicia (MUPEGA). Lembranzas e sensacións. En E. Castro Fustes (Dir. e Coord.). Dez anos do Museo Pedagóxico de Galicia. Santiago de Compostela: Consellería de Cultura, Educación e Ordenación Universitaria, pp. 99-104.

Porto Ucha, A. S.e Iglesias Salvado, J. L. (2010). La JAE y la formación del magisterio gallego: profesores de Escuelas Normales, inspectores y maestros becados (1907-1936). En J. M. Sánchez Ron eJ. García-Velasco (Eds.) (2010). 100 JAE. La Junta para Ampliación de Estudios e Investigaciones Cientificas en su Centenario, t. 2. Madrid: Fundación Francisco Giner de los Ríos - Publicaciones de la Residencia de Estudiantes, pp. 731-757.

Sáenz de la Calzada, M. (1986). La Residencia de Estudiantes (1910-1936). Madrid: CSIC.

Tuñón de Lara, M. (1984). Medio siglo de cultura española (1885-1936). Madrid: Tecnos.

Vázquez Ramil, R. (2012). Mujeres y educación en la España contemporánea. La Residencia de Señoritas de Madrid (1915-1936). Madrid: Akal.

Zulueta, C. de (1984). Misioneras, feministas, educadoras. Historia del Instituto Internacional. Madrid: Castalia.

\section{Documentación consultada}

Arquivo da Residencia de Señoritas de Madrid (ARSM).

Minuta de carta de María de Maeztu a Alberto Jiménez Fraud, Madrid, 5 de xullo de 1922. Caixa: Correspondencia de la Dirección, $\mathrm{n}^{\mathrm{o}}$ orden 56 , signatura 54.

Escritura de compromiso de venta outorgada por don Juan de Isasa y del Valle, a señorita May Gardner e don Ramón Menéndez Pidal o 4 de agosto de 1924 ante don José Menéndez y de Parra, abogado e notario do Ilustre Colegio desta Corte. Caixa 6, carpeta 9.

Minuta de carta de María de Maeztu al Ilmo. Sr. Presidente de la Junta para Ampliación de Estudios, 1928. Caixa: Comité de Boston, sig. 7, nº 9. 
Biblioteca do Museo de Pontevedra (B.M.P.)

Legado López Suárez - Castillejo.

Biblioteca da Real Academia da Historia (B.R.A.H.)

Fondo Giner de los Ríos, Caja 10, Sobre 1900 (A-C). Sobre 1901 (A-C).

Fundación Penzol (Vigo)

Fondos Orgánicos de X. V. Viqueira

Instituto «Pai Sarmiento» de Estudos Galegos (Santiago de Compostela)

Boletín de la Institución Libre de Enseñanza(BILE)

Junta para Ampliación de Estudios (JAE)

Anais e Memorias (1907-1936).

Misión Biolóxica de Galicia (Salcedo, Pontevedra) e AHUS (Sección Histórica, Legaxo 340).

Memoria referente al funcionamiento de la Misión Biológica de Galicia tanto en lo que afecta a la parte económica de la misma como a la eficacia de los trabajos que lleva a efecto, formulada por don Marcelino de Arana y Franco, Consejero-Inspector del Cuerpo de Ingenieros Agrónomos y representante de la Dirección General de Agricultura en la Comisión de Vigilancia de dicho Centro, año 1935. 